\title{
Analysis of the relationship between seismic moment and fault length for large crustal strike-slip earthquakes between 1977-92
}

\author{
G. Pegler ${ }^{1}$ and S. Das \\ Department of Earth Sciences, University of Oxford, Oxford, England
}

\begin{abstract}
We have used an uniform data set to determine the scaling relation between seismic moment $M_{0}$ and fault length $L$ for 34 large, crustal, strike-slip earthquakes in the period 1977-92. The seismic moments used were obtained by the centroid-moment tensor analysis. The aftershocks of each event were relocated in this study and the fault length estimated from their spatial extent. For large events, we find that in spite of some scatter in the data, the trend of this uniform data set indicates that $M_{0} \propto L^{2}$. Our data set does not show any obvious change of slope around $M_{0} \approx(.6-.8) \times$ $10^{20} \mathrm{~N} \mathrm{~m}$ as was seen in a previous non-uniform data set in Romanowicz [1992].
\end{abstract}

\section{Introduction}

The scaling of seismic moment $M_{0}$ with fault length $L$ has long been understood to be of fundamental importance in seismology and has been studied by many authors. Scholz [1982] gave a compilation of data for large events in his study of this relationship and discussed its physical implications. Namely, if $M_{0} \propto L^{2}$, it implies that the average slip is proportional to the fault length. On the other hand, if $M_{0} \propto L$, this would imply that the average slip is independent of the fault length. Scholz [1982] concluded that his data indicated a slope of $M_{0} \propto L^{2}$ for large earthquakes, and called this the "L-model". Shimazaki [1986] found a similar relation for large earthquakes in Japan.

In the last three years there has been renewed debate in the literature concerning these scaling relationships (Romanowicz [1992], Scholz [1994a], Romanowicz [1994], and Scholz [1994b]). In view of the fact that recent dynamic calculations on heterogeneous faults with highly rate-dependent friction are consistent with the L-model (Cochard [1995]), it is important to re-examine the data that had been used by Romanowicz [1992]. That data comes from a wide variety of sources in which both fault lengths and moments have been calculated using many different techniques, with varying degrees of reliability. The lengths have been determined from observed surface displacements, from aftershock distributions and from wave-form analysis. The moments, mostly taken from Purcaru and Berckhemer [1982], have been determined

\footnotetext{
${ }^{1}$ Now at StatSci Europe, Osney House, Mill Street, Oxford, U. K.
} Copyright 1996 by the American Geophysical Union.

Paper number 96GL00963

0094-8534/96/96GL-00963\$05.00 using surface wave and free oscillation data, body wave data, aftershock areas and an empirical $M_{0}$ vs. area relation, tsunami magnitudes and other even less reliable methods (such as field evidence of fault area and slip). Much of the data comes from earthquakes that occurred before the deployment of digital instruments in 1977. Clearly the uncertainties in moment for pre-1977 events are far greater than those for post-1977 data for which centroid moment tensor (CMT) solutions exist.

It is essential, however, to analyze all events in an uniform manner when comparing their scaling characteristics, so that the bias inherent in the different methods are minimized. In order to do this, we shall consider only earthquakes for which a reliable seismic moment estimate is available from CMT analysis and shall relocate the aftershocks for every event studied in order to obtain an uniform estimate of $L$. We systematically study the largest strike-slip earthquakes that occurred between 1977-92 and investigate the relationship between $M_{0}$ and $L$ for these earthquakes.

\section{Data selection and Methodology}

The seismic moments used in this study were taken from the Harvard CMT catalogue (Dziewonski et al. [1983-1994]) which commences in 1977 . We select events for which both nodal planes of the CMT mechanism have dips greater than $60^{\circ}$ and for which the rakes lie within $\pm 15^{\circ}$ of $0^{\circ}, 180^{\circ}$ or $-180^{\circ}$. We further restrict this study to crustal events with hypocentral depths given by the International Seismological Center (ISC) in the range $0-33 \mathrm{~km}$. There were no large strike-slip events in the $33-100 \mathrm{~km}$ range during the period under study (see footnote of Table 1 regarding ISC depth error in event \#17). Fault lengths were determined from the spatial extent of aftershocks relocated using ISC phase arrival time data, which is only available up to the end of 1992 at present. We therefore restrict our study to earthquakes in the period 1977-92 and use either the Joint Hypocenter Determination (JHD) method or the master event method (Dewey, [1971, 1983]) to relocate the aftershocks of each event. We study all events with $M_{0}>1 \times 10^{20} \mathrm{~N} \mathrm{~m}$. For smaller events, we have chosen only to study those earthquakes for which we have a sufficient number of aftershocks to be truly representative of the fault length, usually with a few $m_{b} \leq 4.0$ aftershocks reported by the ISC, so as not to underestimate the lengths of small events due to a lack of nearby stations.

Whether or not fault lengths are more accurately determined from field observations, waveform analyses or after- 


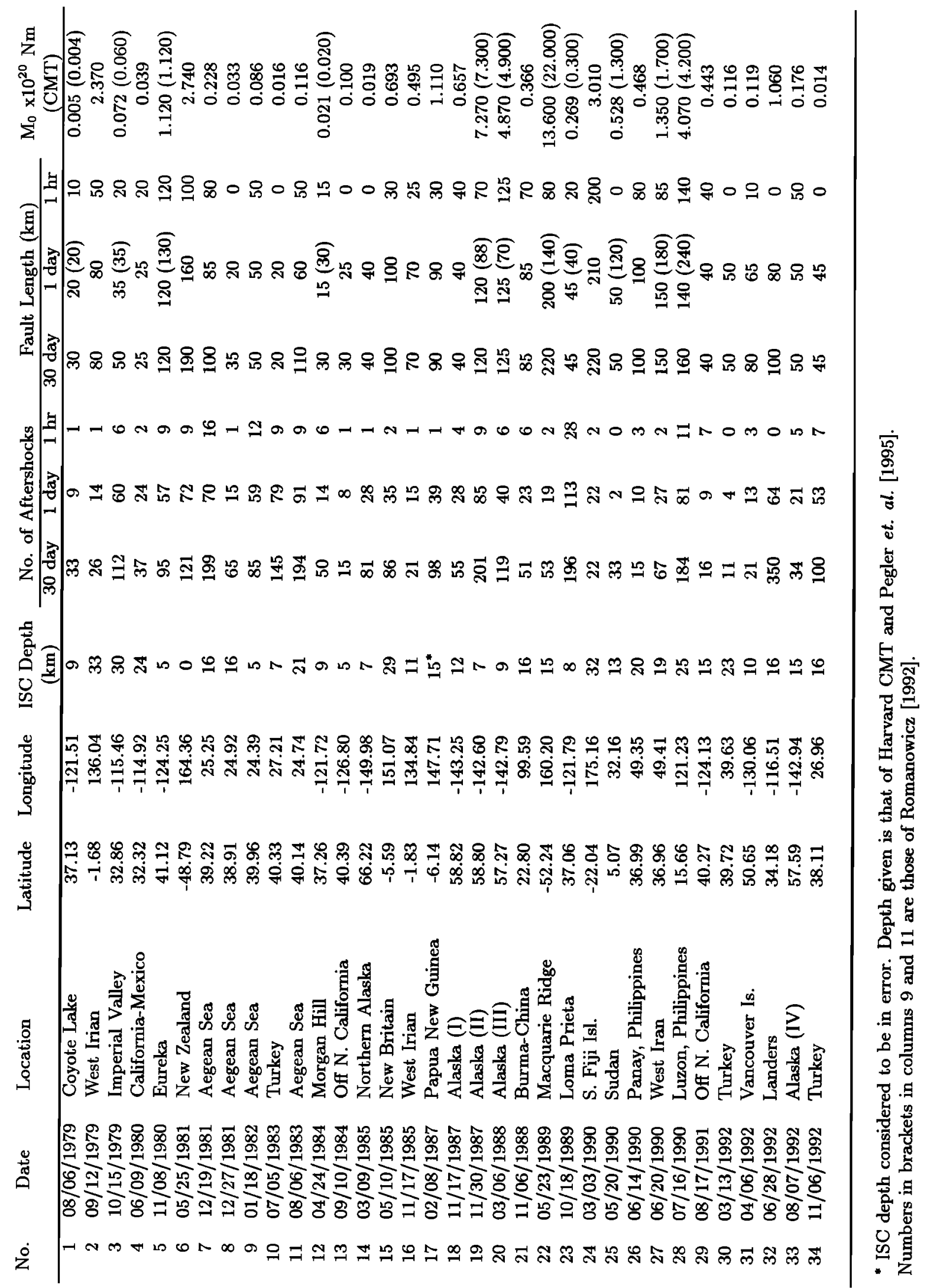


shock distribution analyses is not clear. A uniform measure applied to all earthquakes is, however, desirable to allow comparison between events and to minimize biases inherent in such determinations. In this study it is assumed that the distribution of aftershocks is a valid method of measuring the fault length for the main shock. Each event and its 30-day aftershock sequence were relocated, using either the JHD or the master event method. The choice of whether to use the JHD or the master event relocation procedure depended on the number of events, their magnitude and the number of stations recording each aftershock sequence. The data analysis and other relevant details are fully reported in Pegler [1995], together with figures and tables showing the relocated aftershocks for each event.

\section{Results}

The results of this study are shown in Table 1. The fault lengths estimated from 1-hour, 1-day and 30-day aftershock distributions are tabulated. For most events, there is no significant difference between the 1-day aftershock lengths and that derived from longer periods of time (Pegler, [1995]). Half of the events in this study have fewer than four aftershocks reported by the ISC within one hour of the main shock, and using the fault lengths determined from the distribution of one hour aftershocks may significantly underestimate the fault lengths. The one day aftershocks typically represent $30-60 \%$ of the one month aftershocks and are considered to be the best measure of the fault length.

Recent work by Cifuentes [1995] shows that the CMT moment may underestimate the moment of large events. The only event from this study for which Cifuentes [1995] finds the moment is the 1989 Macquarie Ridge event $\left(M_{w} \approx 8.2\right)$. We have used the CMT moment of $13.6 \times 10^{20} \mathrm{~N} \mathrm{~m}$ and $\mathrm{Ci}$ fuentes [1995] finds a moment of $16.8 \times 10^{20} \mathrm{~N} \mathrm{~m}$, a difference which is barely distinguishable on our plot.

The data presented in this study overlaps with some data used in Romanowicz [1992] between the years 1977-90 and for the common events that data is included in parenthesis in Table 1. Detailed discussion of differences and errors in the data used by Romanowicz [1992] is given in Pegler [1995]. Table 1 shows that the moments for nine of the events common to both studies are in agreement and only two differ. The lengths, however display a greater degree of dissimilarity.

Figure 1 (a) shows the rupture length $L$ estimated in this study from the 1-day aftershock distribution, against $M_{0}$. In addition to the 34 events studied here, we also include some large, pre-1977 events from Romanowicz [1992] in Figure 1 (a) and list their parameters in Table 2. In Figure 1(b) we show only the data from this study but indicate also the 30-day aftershock length estimated in this study, for all the events. These may be taken as a measure of the error in the lengths determined. The figure shows that it is only for a few of the smaller events that there is any difference between these two estimates. We also plot lines with slopes of $\frac{1}{2}$ in Figure 1 (b). It is seen that whether one uses the rupture length based on the 1-day or 30-day aftershock distribution does not change the trend of the data. Of the five pre-1977
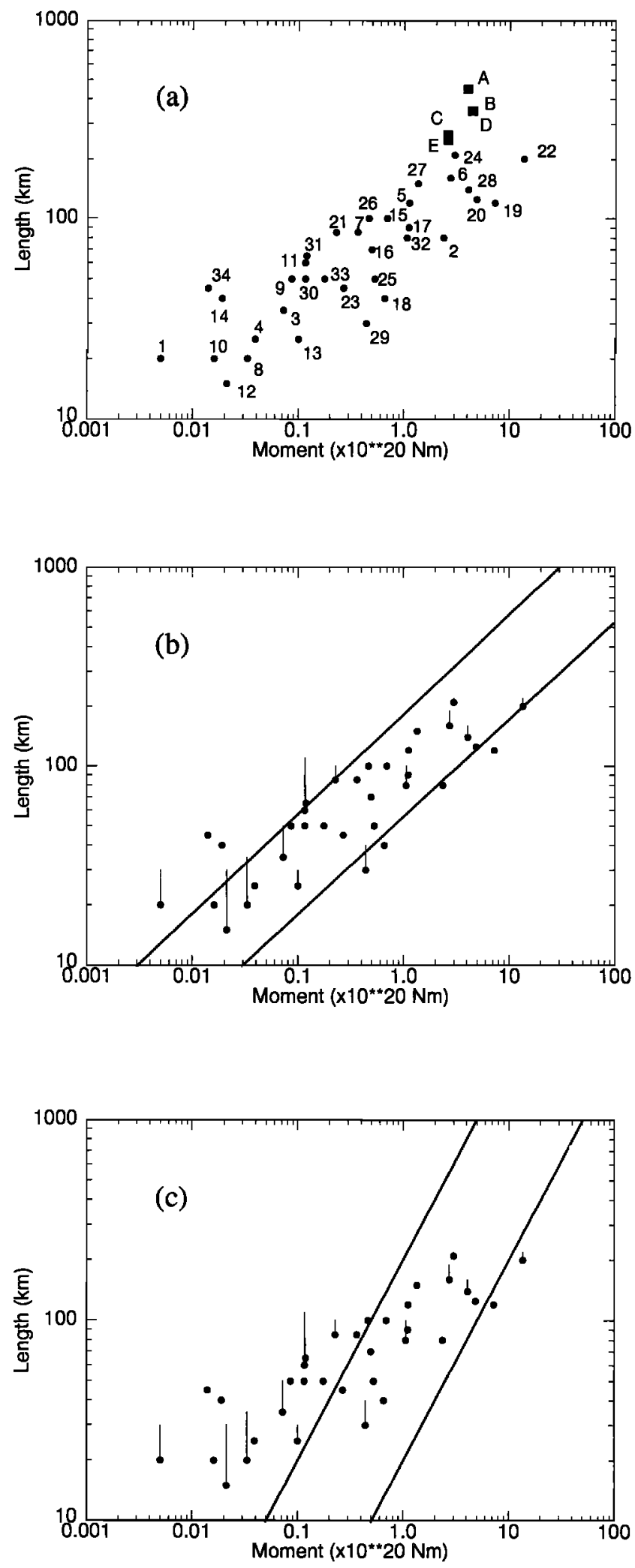

Figure 1. (a) Plot of $\log M_{0}$ against $\log L$ using 1-day aftershock lengths obtained in this study, shown by dots. The numbers next to the dots associate the earthquake with its parameters listed in Table 1. The data from old earthquakes, listed in Table 2, are shown by squares with identifying letters next to them. (b) Straight lines of slope $\frac{1}{2}$, superimposed on the data. The 30-day aftershock lengths are indicated by the line-segments. (c) Same as (b) but with lines of slope 1 superimposed on the data. 
TABLE 2

\begin{tabular}{cclcc}
\hline & Date & Location & L (km) & Mo $^{*}$ \\
\hline A & $04 / 18 / 1906$ & San Francisco & 450 & 4.0 \\
B & $12 / 26 / 1939$ & Turkey & 350 & 4.5 \\
C & $11 / 26 / 1943$ & Turkey & 265 & 2.6 \\
D & $07 / 10 / 1958$ & Alaska & 350 & 4.4 \\
E & $02 / 04 / 1976$ & Guatemala & 250 & 2.6 \\
\hline \multicolumn{5}{c}{ "x10 ${ }^{20}$ N m }
\end{tabular}

events, only the 1906 California earthquake would fall outside the band shown. Thus the data for the large events listed in Table 2 are not inconsistent with these conclusions, except for this one very old earthquake. Though not plotted here, the data of Purcaru and Berckhemer [1982] does not change the trend of the data. Finally, in Figure 1 (c), we show only our data and lines with slopes of 1 .

\section{Conclusions}

Figure 1 shows that the fault lengths of large strike-slip earthquakes increase with moment but there is some scatter in the data. This diffuse zone can be better described as a band with a slope of $\frac{1}{2}$ rather than by a slope of 1 , suggesting that $\mathrm{M}_{0} \propto L^{2}$ for large earthquakes, as suggested by the observations of Scholz [1982], of Shimazaki [1986] and by theoretical calculations of Cochard [1995]. Our uniform data set does not indicate any change of slope around $M_{0} \approx(.6-.8) \times 10^{20} \mathrm{~N} \mathrm{~m}$ as suggested by Romanowicz [1992], based on a non-uniform data set.

It is important to note that except for a few points, our data is not very different from that used by Romanowicz [1992], and the differences are generally less than the widths of the bands shown in Figure 1. We suggest that the different conclusion reached by us comes not from a fundamental difference in the data but from the way Romanowicz [1992] did the regression. We also suggest that the diffuse nature of the $\log$ $M_{0}$ versus $\log L$ relationship obtained in this study is more representative of the true scatter in the data and that more or better data may not necessarily reconcile this debate.
Acknowledgments. One of the authors (G. P.) was supported by the NERC studentship GT4/91/GS/109. We would like to thank Jim Dewey for use of his earthquake relocation programs.

\section{References}

Cifuentes, I. L., Seismic moment and duration of recent large and great earthquakes, J. Geophys. Res., 100, 20,303-20,309, 1995.

Cochard, A., Dynamique de la rupture sismique: frottement et complexite, These de Doctorat de l'Universite Paris 7, France, 1995.

Dewey, J. W., Seismicity studies with the method of joint hypocenter determination: Berkeley, Calif., University of Califormia at Berkeley Ph. D. thesis, 163 pp., 1971.

Dewey, J. W., Relocation of instrumentally recorded pre-1974 earthquakes in the South Carolina region, in Gohn, G. S., ed. Studies related to the Charleston, South Carolina, earthquake of 1886-tectonics and seismicity: U. S. Geological Survey Professional Paper 1313, p. Q1-Q9, 1983.

Dziewonski, A. et al., Centroid-moment tensor solutions 1977 1992, Phys. Earth. Planet. Int., 33-83, 1983-1994.

Pegler, G., Studies in seismotectonics, D. Phil thesis, University of Oxford, U. K., 1995.

Pegler, G., S. Das and J.H. Woodhouse, A seismological study of the Eastem New Guinea and Western Solomon Sea regions, Geophys. J. Int., 122,961-981, 1995.

Purcaru, G. and H. Berckhemer, Quantitative relations of seismic source parameters and a classification of earthquakes, Tectonophys., 84, 57-128, 1982.

Romanowicz, B., Strike-slip earthquakes on quasi vertical transcurrent faults: Inferences for general scaling relations, Geophys. Res. Lett., 19, 481-484, 1992.

Romanowicz, B., Comments on "A reappraisal of large earthquake scaling", Bull. seismol. Soc. Am., 84, 1675-1676, 1994.

Scholz, C.H., Scaling laws for large earthquakes: consequences for physical models, Bull. seismol. Soc. Am., 72, 1-14, 1982.

Scholz, C.H., A reappraisal of large earthquake scaling, Bull. seismol. Soc. Am., 84, 215-218, 1994a.

Scholz, C.H., Reply to comments on "A reappraisal of large earthquake scaling”, Bull. seismol. Soc. Am., 84, 1677-1678, 1994 b.

Shimazaki, K., Small and large earthquakes: The effects of the thickness of seismogenic layer and the free surface, in Earthquake Source Mechanics, AGU Monograph 37, eds. S. Das, J. Boatwright and C. H. Scholz, 209-216, 1986.

G. Pegler and S. Das, Department of Earth Sciences, University of Oxford, Parks Road, Oxford OX1 3PR, U. K.

(e-mail:geoff@earth.ox.ac.uk)

(received November 27, 1995; revised March 17, 1996; accepted March 21, 1996.) 